\title{
MFAP5 promotes basal-like breast cancer progression by activating the EMT program
}

\author{
Yanmei Wu ${ }^{1 \dagger}$, Ping $\mathrm{Wu}^{2 \dagger}$, Quan Zhang ${ }^{1}$, Wenjin Chen ${ }^{3}$, Xishui Liu ${ }^{1 *}$ and Weiqiang Zheng ${ }^{4^{*}}$ (1)
}

\begin{abstract}
Purpose: Human basal-like breast cancer (BLBC) is an aggressive malignancy with poor prognosis. Since most current treatments are ineffective, there is an urgent need to identify therapeutic targets for BLBC. Microfibrillarassociated protein 5 (MFAP5) plays an important role in the integration of elastic microfibers and the regulation of endothelial cell behaviors. We previously demonstrated that MFAP5 was significantly overexpressed in BLBC tissues and associated with poor metastasis-free survival of patients with BLBC. However, the detailed role of MFAP5 in BLBC is unclear. Thereby, the current study aimed to investigate the underlying function of MFAP5 in BLBC.

Method: Functional analyses were conducted for the role of MFAP5 in BLBC in vitro and in vivo.

Results: Overexpression of MFAP5 resulted in a significant increase in the proliferation, migration, invasion and epithelial-mesenchymal transition (EMT) markers in BLBC in vitro and in vivo. In addition, other metastasis animal models by tail intravenous injection of BT20 cells further confirmed that MFAP 5 overexpression promoted BLBC proliferation and BT20 cells metastasis. We found that the TGF- $\beta$ or Notch inhibitor significantly reversed the tumorigenicity and metastasis of MFAP5-induced BLBC cells.
\end{abstract}

Conclusion: Our findings suggest that MFAP5 may promote EMT in BLBC metastasis via the TGF- $\beta$ /Notch pathway.

Keywords: MFAP5, Basal-like breast cancer, EMT, TGF- $\beta$, Notch

\section{Introduction}

Breast cancer is the second leading cause of cancer for women mortality worldwide [1]. According to gene expression profiling, it can be classified into four major molecular subtypes: luminal A, luminal B, human epidermal growth factor receptor 2 (HER2) and human basallike breast cancer (BLBC) [1]. BLBC has low expression of the estrogen receptor (ER), progesterone receptor (PR) and HER2 gene, while the expression of basal cytokeratins (CK5/6, CK14, and CK17), epidermal growth factor receptor (EGFR), c-kit and p53 are transcriptionally

\footnotetext{
*Correspondence: Sunnyliu8001@126.com;

Zhengweiqiang_ch@sina.com

${ }^{\dagger}$ Yanmei Wu and Ping Wu contributed equally to this work and should be considered as co-first authors

${ }^{1}$ Department of Breast Surgery, Changhai Hospital, Naval Medical

University, 800 Xiangyin Road, Shanghai 200433, China

${ }^{4}$ Department of Pathology, Changhai Hospital, Naval Medical University,

Shanghai 200433, China

Full list of author information is available at the end of the article
}

upregulated $[1,2]$. People suffered from BLBC present with aggressive clinical behaviors, such as high histologic grade, distant metastasis to the lung and brain within 3-5 years, a poor prognosis and short disease-free and overall survival $[3,4]$. Currently there is still no targeted treatment for BLBC and the only choice of chemotherapy is not effective as well $[5,6]$. Therefore, it is very urgent for us to investigate the underlying molecular mechanisms of BLBC metastatic process and find a new therapeutic target.

Some researches define BLBC for its negative expression of triple-negative phenotype (ER, PR and HER2), but several evidences have demonstrated that BLBC is not synonymous with triple-negative breast cancer $[7,8]$. Utilizing additional immunohistochemistry (IHC) markers such as basal cytokeratins and EGFR have proven to be better in defining BLBC than triple-negative phenotype, but the disadvantage is the lacking of accuracy [9, 10]. Thus validation of a diagnostic test and the accurate 
single marker for identification of BLBC in the clinic remains a bottleneck $[6,11]$.

Matysiak et al. [12] stated that epithelial-mesenchymal transition (EMT) promoting transcription factors were negative prognostic markers in breast cancer based on a review of current available literatures. During EMT process, a variety of signaling pathways are involved in the activation of EMT such as tumor growth factor- $\beta$ (TGF$\beta$ ), nuclear factor- $k B(N F-\kappa B)$, Notch, RTK/Ras, Wnt/ $\beta$ catenin pathways [13]. Li [14] found that LKB1/AMPK could be used as a target of TGF- $\beta$ pathway in breast cancer cells to control the development of breast cancer. TGF- $\beta$ induces cell cycle to arrest in G0/G1 phase, and in the TGF- $\beta$ signaling pathway STIM1 and store-operated calcium entry (SOCE) play an anti-proliferative role in breast cancer [15]. In addition, more and more evidences have shown that Notch1 overexpression is strongly associated with breast cancer invasion, which is an important factor in maintaining the malignant phenotype of breast cancer stem cells [16]. Notchl signaling also correlates with self-renewal and differentiation of breast cancer stem cells (CSCs) and their malignant behaviors [17].

Microfibrillar-associated protein 5 (MFAP5), previously known as MAGP2, is a multifunctional secretion protein, which plays an important role in the integration of elastic microfibers, regulation of endothelial cell behavior and cell survival [18-21]. Mok et al. [22] had demonstrated that MFAP5 can be used as an independent adverse prognosis predictor via studying of a group of advanced ovarian serous papillary adenocarcinomas. Some genes such as FGF18, FGFR2, ADAM12, NEDD9, MMP13 and CDC2 were also up-regulated in the related signaling pathway, which indicated that MFAP5 is indirectly involved in the regulation of various protein kinase pathways in breast cancer. Other researches also showed that MFAP5 mediates ovarian cancer cell motility and invasion potential through FAK/CREB/TNNC1 signaling pathways, suggesting that it may be a new modality of ovarian cancer treatment [23]. Moreover, some researchers also found that there was a significant correlation between MFAP5 and lymph node metastasis, tumor metastasis and patient's overall survival in early tongue cancer [24]. This study also pointed out MFAP5 might be a mysterious target to predict the prognosis of cervical cancer and tongue cancer metastasis [24].

In the previous study, we set out to systematically analyze the gene chip containing 48, 804 test genes to identify specific biomarkers for BLBC, and confirmed that the MFAP5 gene was significantly up-regulated in BLBC by RT-PCR verification [25]. We also found that overexpression of MFAP5 was significantly correlated with TNM staging and axillary lymph node metastasis in BLBC, suggesting that the MFAP5 gene plays an important role in the development and metastasis of BLBC. Furthermore, we aimed to explore the relationship between MFAP5 expression and EMT phenotypes and investigate the impact of MFAP5 on the invasion and metastasis of BLBC in vitro and in vivo. Finally, the possible involvement of TGF- $\beta /$ Notch pathways was also investigated.

\section{Materials and methods \\ Cell culture, antibodies and reagents}

Human breast cancer cell lines HS578T and BT20 were purchased from American Type Culture Collection. Cells were routinely maintained in Dulbecco's modified Eagle's medium (DMEM, HyClone/Thermo) supplemented with $10 \%$ fetal bovine serum (Biowest), $50 \mathrm{IU} / \mathrm{ml}$ of penicillin, and $50 \mu \mathrm{g} / \mathrm{ml}$ of streptomycin. Cells were kept at $37{ }^{\circ} \mathrm{C}$ in a humidified incubator with $5 \% \mathrm{CO}_{2}$. Phosphate-buffered saline (PBS) with $0.05 \%$ trypsin (Invitrogen) was used for cell harvesting and passage. Antibodies for MAGP2 (MFAP5), Smad2/Smad3 and p-Smad2/Smad3 were purchased from Abcam (Cambridge, UK). Antibodies for $\mathrm{E}$ cadherin, $\mathrm{N}$-cadherin, vimentin and Type I Collagen were purchased from Bioss (Shanghai, China). TGF- $\beta$ inhibitor SB431542 and the Notch inhibitor ly-411575 were purchased from Selleck (USA).

\section{Plasmid construction and transfection Lentivirus production}

MFAP5 related lentivirus plasmid and vehicle were designed and produced by NOVOBIO (Shanghai, China). To overexpress MFAP5, the full-length MFAP5 gene was constructed in the lentiviral vectors PDS087_pL6-TOV5-GIM to obtained PL6-TO-V5-HOMO-MFAP5 vector. To suppress MFAP5, we designed three pairs of Oligo RNA according to the MFAP5 sequence (MFAP5-109-F: CACCGCGACTCCAGAAACATTCACACGAATGTG AATGTTTCTGGAGTCGC; MFAP5-109-R: AAAAGC GACTCCAGAAACATTCACATTCGTGTGAATGTT TCTGGAGTCGC), (MFAP5-330-F: CACCGCACCAGT TTACGACGTATGTACGAATACATACGTCGTAAA CTGGTG; MFAP5-330-R: AAAACACCAGTTTACGAC GTATGTATTCGTACATACGTCGTAAACTGGTGC),

(MFAP5-379-F: CACCGCTTGTCTGTAAGGAACAC G A AC GAA T TC GTG T TC C T T ACA GAC AAG; MFAP5-379-R: AAAACTTGTCTGTAAGGAACACGA ATTCGTTCGTGTTCCTTACAGACAAGC). Three shRNAs specific (PL-shRNA-GFP-homo-MFAP5-109, PL-shRNA-GFP-homo-MFAP5-330, PL-shRNA-GFPhomo-MFAP5-379) for the above sequences using PDS019_pL_shRNA_F lentiviral vectors were acquired. The lentiviruses were produced by transiently transfecting individual lentiviral PL6-TO-V5-HOMOMFAP5 vector, PL-shRNA-GFP-homo-MFAP5-109, PL-shRNA-GFP-homo-MFAP5-330 and PL-shRNA- 
GFP-homo-MFAP5-379 together with packaging and envelope plasmids into HEK-293T cells using Lipofectamine 2000 (Invitrogen). Viral supernatants were collected and passed through $0.45-\mu \mathrm{m}$ syringe filters.

\section{MFAP5-overexpressing cells}

For the transfection, the target human breast cancer cell BT20 were seeded in 6-well plates and allowed to attach overnight. Then, the culture medium was replaced with transfection enhancing solution containing PL6-TOV5-HOMO-MFAP5 lentivirus $(\mathrm{MOI}=20)$. Stable cell line BT20-LV-MFAP5 with MFAP5 overexpression was selected with $1-2 \mu \mathrm{g} / \mathrm{ml}$ BSD. The overexpression of MFAP5 was confirmed by quantitative reverse transcriptase PCR (qRT-PCR), immunofluorescence and Western blotting.

\section{MFAP5-knockdown cells}

The target human breast cancer cell HS578T was infected with 40 MOI lentivirus PL-shRNA-GFP-homoMFAP5-109, PL-shRNA-GFP-homo-MFAP5-330 or PL-shRNA-GFP-homo-MFAP5-379, respectively. The control group was negative control virus infection group and blank cell culture group. Cells were collected after $48 \mathrm{~h}$ to extract RNA. The optimal interference lentivirus PL-shRNA-GFP-homo-MFAP5-330 was screened by RT-PCR detection. MFAP5-knockdown stable cell lines HS578T-MFAP5-shRNA were selected with 1-2 $\mu \mathrm{g} /$ $\mathrm{ml}$ BSD. The knockdown efficiency of MFAP5 was confirmed by qPCR, immunofluorescence and Western blotting.

\section{RNA extraction and quantitative real-time PCR analysis}

Total RNA was isolated using an RNeasy Mini kit (Invitrogen) according to the manufacturer's instructions. Reverse transcription was performed with PrimeScript TM Master Mix (Invitrogen) according to its product manual. Then, the qPCR was performed with SYBR Premix EX TaqTM II (Invitrogen) according to the manual on the CFX96TM Real-Time detection System (BioRad). $\beta$-actin was used as the reference, and the data were analyzed with a normalized gene expression ( $\mathrm{ddCt}$ ) method. All the measurements were performed in triplicate. The sequences of the primer pairs were as follows: (MFAP5 F: GCATCGGCCGGTTAAACAAT, R: TCACAGGGA GGAAGTCGGAA) Hes1 (F: GTGTCAACACGACAC CGGAT, R: GGAATGCCGCGAGCTATCTT), Hes5 (F: AGTCCCTGCCGTTTTAGGAC, R: GAGCCCCGG CACTACAAATA), slug (F: TCTGGGCTGGCCAAA CATAA, R: TTCTCCCCCGTGTGAGTTCTA), Snail (F: CGAGTGGTTCTTCTGCGCTA, R: CTGCTGGAA GGTAAACTCTGGA), Zeb1 (F: ACCTGCCAACAG ACCAGACA, R: TCTTGCCCTTCCTTTCCTGTGT),
Zeb2 (F: AGTGTGCCCAACCATGAGTC, R: ACTGGA CCATCTACAGAGGC), Twist1 (F: GGCCAGGTACAT CGACTTCC, R: CATCCTCCAGACCGAGAAGG).

\section{Immunofluorescence analysis}

Cells were cultured on glass coverslips in a 24-well plate, fixed with $4 \%$ paraformaldehyde, permeabilized using $0.1 \%$ Triton X-100, washed with $1 \times$ PBS, and blocked with $5 \%$ bovine serum albumin. The cells were incubated with MAGP2 primary antibody (1:100 dilution, Abcam), followed by incubation with a Goat Anti-rabbit IgG/ RBITC antibody (1:100 dilution, Bioss). Coverslips were mounted with vectashield mounting medium containing diamidino-2-phenylindole (DAPI, sigma) nuclear stain and examined under an IX51 fluorescence microscope (Olympus), then the images were constructed using software.

\section{In vitro migration and invasion assay Cell proliferation assay}

Cell proliferation was monitored by the colorimetric water-soluble tetrazolium salt (CCK8) assay using a Cell Counting Kit-8 (DOJINDO) according to the manufacturer's instructions. Breast cancer cells were seeded onto 96-well plates $\left(3 \times 10^{3}\right.$ cells/well). Added CCK8 reagent $(10 \mu \mathrm{l} /$ well $)$ at $0,24,48$ or $72 \mathrm{~h}$, respectively. Cells were incubated for another $3 \mathrm{~h}$ at $37{ }^{\circ} \mathrm{C}$. The number of viable cells was assessed by measurement of the absorbance at $450 \mathrm{~nm}$ using a RT-2100C microplate reader (Rayto).

\section{Cell-fibronectin adhesion assay}

The 96-well plates were coated with $10 \mu \mathrm{g} / \mathrm{ml}$ of fibronectin (sclencell). Breast cancer cells $\left(3 \times 10^{3}\right.$ cells/well) were placed at $37{ }^{\circ} \mathrm{C}$ for $30 \mathrm{~min}$, and then rinsed with PBS. The cells were digested and suspended with non-serum medium. Later on, the cells were seeded onto the above 96-well plate at a $90 \%$ density. After adhesion for $30 \mathrm{~min}$ at $37^{\circ} \mathrm{C}$, the cells were washed with PBS for 2 times and then visualized under a microscope. To minimize the bias, at least three randomly selected fields were quantified using $100 \times$ magnification, and the average number of cells was taken.

\section{In vitro scratch assay}

Draw two horizontal lines in the back of the 96-well plate across the hole, plate growing cells at $90 \%$ confluence to form a monolayer. Scrape the cell monolayer in a straight line to create a "scratch" with a p200 pipet tip. Remove the debris and smooth the edge of the scratch by washing the cells once with PBS and then replace with serum-free medium. Place the plate under a phase-contrast microscope and acquire the $0 \mathrm{~h}$ images of the scratch. The cells continued to be cultured in the incubator at $37{ }^{\circ} \mathrm{C}$ 
for $24 \mathrm{~h}$. After the incubation, the plate was placed under a phase-contrast microscope, the reference point was matched, and the photographed region acquired images were aligned. The cell migration distance in the same field of views was analyzed and the effect of MFAP5 on cell migration ability was compared.

\section{Transwell migration assay}

BT-20 cells were cultured in serum-free medium for $24 \mathrm{~h}$, digested and suspended in $100 \mu \mathrm{l}$ serum-free medium. The cell density was adjusted t to $5 \times 10^{5} / \mathrm{ml}$ and they were seeded into the upper chamber of a transwell inserted with an 8-mm pore size membrane (Corning). The culture medium chemoattractant of the upper and down transwell chamber was adjusted according to the experimental needs. After incubation for $24 \mathrm{~h}$ at $37{ }^{\circ} \mathrm{C}$, non-migrated cells in the upper chamber of the transwell insert were removed with a cotton swab, and the migrated cells on the underside of the filter membrane were fixed and stained with $0.1 \%$ crystal violet. The number of migrated cells was counted in five randomly selected microscopic fields and photographed. The experiments were independently repeated thrice.

\section{In vitro angiogenesis assay}

The matrigel (Yeasen) solution was applied to 96-well plate at $50 \mu \mathrm{l}$ per well. The matrix gel was placed on ice for $20 \mathrm{~min}$, then incubated at $37{ }^{\circ} \mathrm{C}$ for $24 \mathrm{~h}$. Cells (BT20 mock, BT20-LV-vehicle, BT20-LV-MFAP5, HS578T mock, HS578T-control-shRNA and HS578TMFAP5-shRNA) were cultured at 50\% density in freeserum medium for $48 \mathrm{~h}$, and then cell supernatant was collected, respectively. HUVEC cells were suspended with $100 \mu$ l the above cell supernatant and added to the matrix-coated 96-well plate. Positive control (complete culture with 10\% FBS) and negative control (serum-free basal medium) group were established and continued to be cultured for $6 \mathrm{~h}$. Each well was placed under inverted microscope, and pictures were taken to observe the angiogenesis and analysis the average length of blood vessels.

\section{Western blotting}

Cells were harvested from cultured dishes and were lysed for $30 \mathrm{~min}$ in cold lysis buffer. Cell extracts were collected and centrifuged at $13,000 \mathrm{rpm}$ for $15 \mathrm{~min}$. Total proteins from whole cell lysates were boiled for $10 \mathrm{~min}$ in $1 \times$ SDS buffer, resolved by $12 \%$ SDS-PAGE, and then electrotransferred to nitrocellulose membranes. After the electrophoretic transfer, the membranes were blocked with $5 \%$ non-fat milk in Tris-buffered saline. After blocking the membranes were incubated overnight at $4{ }^{\circ} \mathrm{C}$ with primary antibodies at recommended concentration. The antibodies for Smad2/Smad3, phospho-Smad2/Smad3,
E-cadherin, $\mathrm{N}$-cadherin, vimentin and Type I collagen were purchased from Abcam Technologies. Then, the membranes were incubated with horseradish peroxidase-conjugated secondary antibodies (anti-rabbit or anti-mouse IgG) (Abcam). Signals were detected with immobile Western chemiluminescent HRP Substrate (Millipore). $\beta$-actin (Abcam) was served as the loading control.

\section{Tumorigenicity assays}

All animal experiments were carried out under a license from the Institutional Animal Care and Use Committee at Second Military Medical University. For tumorigenicity and metastasis of human breast cancer in vivo, $5 \times 10^{6}$ of BT20-LV-vehicle and BT20-LV-MFAP5 cells which suspended in PBS were injected into the 4 weeks old nude immunocompromised mice (Shanghai SuperB\&K Laboratory). In experiment 1, BT20-LV-vehicle and BT20-LV-MFAP5 cells were injected into the mammary fat pad of nude mice respectively. In experiment 2, the nude mice were transduced with BT20-LV-vehicle or BT20-LV-MFAP5 cells by tail intravenous injection. From the 2nd week after tumor cell inoculation, tumor size was monitored once a week and determined with caliper. Four to eight weeks from the onset of the study, the mice were photographed and anesthetized; the tumors were removed and weighted.

In order to analyze the metastasis of tumors, the left axillary lymph nodes of mice in experiment 1 were taken to evaluate the tumor metastatic focus by IHC and RTPCR assays. Mice in experiment 2, lungs were dissected to analyze metastases situation.

\section{Immunohistochemistry (IHC)}

The mouse tumor tissues were fixed in $10 \%$ neutralized formalin and embedded in paraffin blocks. Sections (5 $\mu \mathrm{m})$ were then prepared for immunohistochemical examination. After deparaffinization and rehydration, antigen retrieval was performed by boiling in $0.01 \mathrm{mmol} / \mathrm{L}$ citrate buffer $(\mathrm{pH} 6.0)$ for $15 \mathrm{~min}$. After inhibition of endogenous peroxidase activity for $30 \mathrm{~min}$ with methanol containing $3 \% \mathrm{H}_{2} \mathrm{O}_{2}$. The sections were blocked with $2 \%$ bovine serum albumin in PBS for $30 \mathrm{~min}$ and incubated with primary antibody overnight at $4{ }^{\circ} \mathrm{C}$. Staining with secondary antibodies (EnVision) was then performed before development using DAB substrate (Dako) according to the manufacturer's procedure. The cytoplasm was counterstained with hematoxylin.

\section{RNA sequencing and data analysis}

Total RNA samples were obtained to generate RNA libraries for each sample. After the samples were qualified, mRNA was fragmented by heating. These short 
mRNA and random hexamers were used to generate the first cDNA and then the second cDNA was synthesized. The second cDNA was purified using VAHTSTM DNA Clean Beads (Vazyme) and then ligated to sequencing adapters. The fragments were amplified by using polymerase chain reaction (PCR) and purified using VAHTSTM DNA Clean Beads and then sequenced using an Illumina HiSeq (Vazyme). Raw sequence data were assessed, and sequences containing adaptor tags and those of low quality were excluded. DESeq [26] was used to normalize RNA-seq fragment counts to compare the relative abundances of transcripts, and nbinomTest method was used to test for differential expression between cases and controls. Only differentially expressed genes with $P$-value $<0.05$ and an absolute $\log 2$ foldchange $>2$ were selected for differentially expressed genes. The differentially expressed genes were also used for Gene Ontology (GO) and Kyoto Encyclopedia of Genes and Genomes (KEGG) analysis [27].

\section{Statistical analysis}

Results were expressed as mean $\pm \mathrm{SD}$. For comparisons between two different groups, statistical significance was determined using the Student's t-test. A Kruskal-Wallis test followed by Dunn's post hoc test and one-way ANOVA followed by Bonferroni post hoc test were used to determine non-parametric data and continuous variables, respectively. Data were analyzed with GraphPad Prism. In all statistical tests, $P<0.05$ was considered statistically significant.

\section{Results}

MFAP5 expression levels in human breast cancer cell lines In order to choose the proper BLBC cell lines, the MFAP5 level in human breast cancer cell lines BT20 and HS578T was analyzed. Quantitative real-time PCR demonstrated HS578T cells had higher level of MFAP5 than BT20 cells (Additional file 1: Table S1). Finally, we selected HS578T (higher expression of MFAP5) and BT20 (lower expression of MFAP5) for the following studies.

\section{MFAP5 promoted cancer cell proliferation, adhesion, migration and invasion in vitro}

To determine the role of MFAP5 in BLBC, we transfected BT20 cells with MFAP5 lentivirus to obtain stable cell line BT20-LV-MFAP5 with MFAP5 overexpression. Besides, to inhibit the expression of MFAP5, HS578T cells were transfected with MFAP5 shRNA. The results of qRT-PCR confirmed that MFAP5 was overexpressed in BT20-LV-MFAP5 cells and downregulated in HS578TMFAP5-shRNA cells (Additional file 2: Figure S1).

Next, we examined the function of MFAP5 in breast cancer cells. CCK8 assay revealed that BT20 cells transfected with MFAP5 lentivirus grew more rapidly than those transfected with vehicle (Fig. 1a). In contrast, compared with control shRNA group, cells in HS578TMFAP5-shRNA group showed decreased cell viability (Fig. 1b). These data indicated that MFAP5 promoted BLBC growth in vitro. The cell-fibronectin adhesion assay revealed that overexpression of MFAP5 stimulated the adhesion of BT20 cells (Fig. 1c). When the MFAP5 gene was knocked down in HS578T cells, the adhesive behavior was decreased significantly (Fig. 1d). Next, we further assessed the effects of MFAP5 on cell migration, a key determinant of malignant progression and metastasis. As shown in Fig. 1e, overexpression of MFAP5 significantly increased BT-20 cells migration, while knockdown of MFAP5 in HS578T cells, the scratch wound-healing motility were decreased markedly (Fig. 1f). These results indicated MFAP5 promoted cell motility.

In addition, invasive rate in breast cells was detected using a transwell assay. As shown in Fig. 2a, b, overexpression of MFAP5 promoted BT-20 cell invasion, while the ability of cell invasion was significantly weakened by MFAP5 knockdown in HS578T cells compared with those in control shRNA group. We also discovered the supernatant of BT20-LV-MFAP5 cells could promote the invasion of BT20 cells (Fig. 2c). Similarly, the invasion of HS578T cells was decreased by the supernatant of HS578T cells transfected with MFAP5 shRNA (Fig. 2d). These results proposed a functional role for MFAP5 in mediating cell migration and invasion in BLBC cells in vitro.

\section{MFAP5 induced angiogenesis of HUVEC cells}

To explore the role of MFAP5 on angiogenesis, we cultured HUVEC cells with the supernatant of BT20-LVvehicle and BT20-LV-MFAP5 cells and found the average length of the HUVEC blood vessels in supernatant of BT20-LV-MFAP5 group was about three times of that in BT20-LV-vehicle group (Fig. 3a). In contrast, comparing with HUVEC cells in the supernatant of HS578T-control-shRNA cells, the average length of the blood vessels decreased in HS578T-MFAP5-shRNA cells supernatant (Fig. 3b). These results showed that MFAP5 could promote the angiogenesis of HUVEC cells.

\section{MFAP5 promoted BLBC tumor growth and metastasis in vivo}

To determine the effect of MFAP5 on BLBC tumor growth in vivo, stable BT20-LV-MFAP5 cells with modified MFAP5 expression and normal control BT20-LVvehicle cells were respectively injected into two groups of nude mice. In experiment 1 , the volume of tumors in BT20-LV-MFAP5 nude mice was much bigger than that in BT20-LV-vehicle group (Fig. 4a). Besides, the weight 


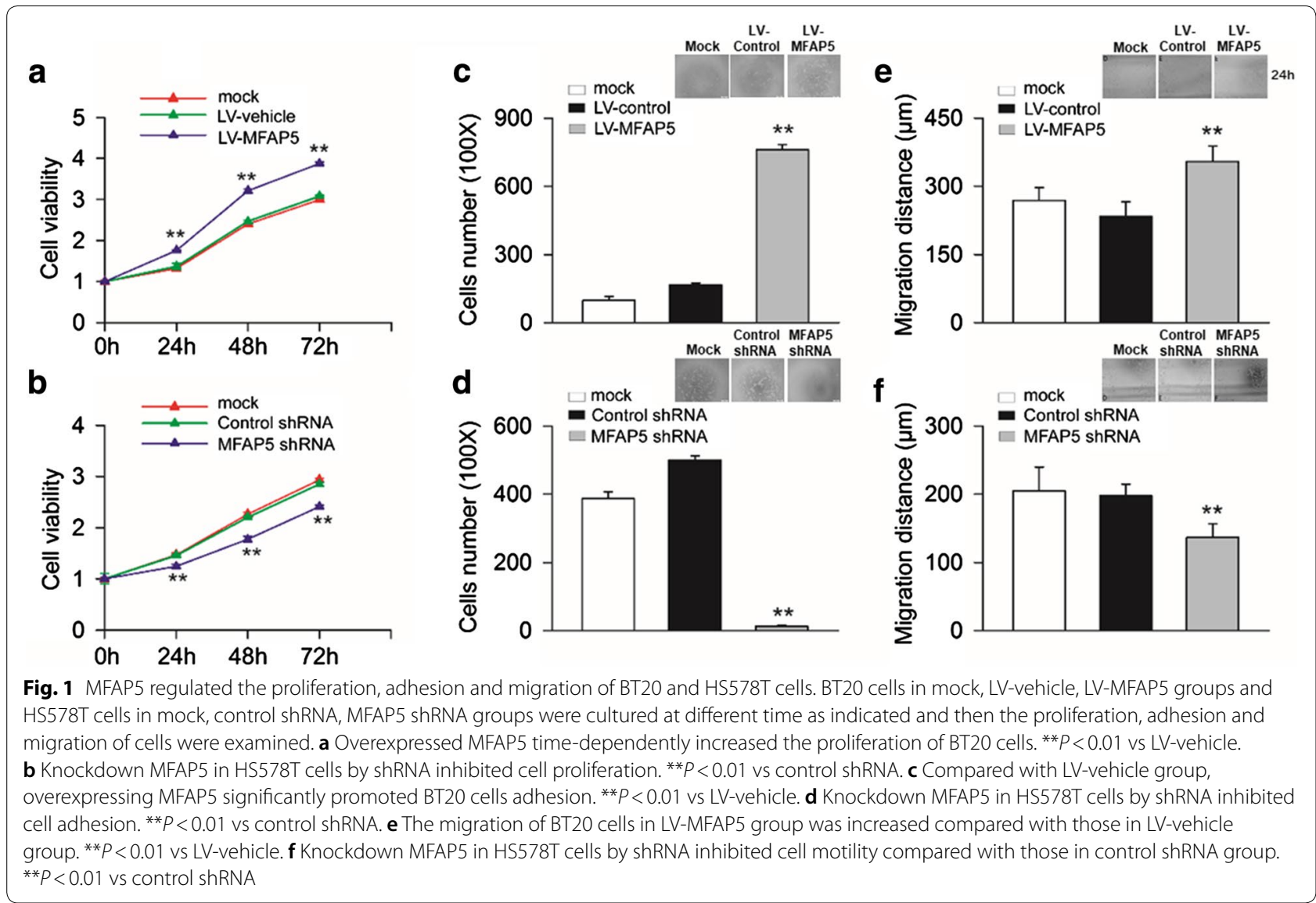

of tumors in BT20-LV-MFAP5 nude mice $(0.38 \pm 0.08 \mathrm{~g})$ was significantly increased compared with that in BT20LV-vehicle group $(0.22 \pm 0.09$ g) (Fig. 4b). IHC showed axillary lymph nodes metastasis of BT20-LV-MFAP5 group was more serious than BT20-LV-vehicle cells. qRTPCR results further demonstrated that the GFP mRNA expression of axillary lymph nodes in BT20-LV-MFAP5 group $(8.47 \pm 1.23)$ was about 8 times higher than that in BT20-LV-vehicle group $(1.04 \pm 0.31)$ (Fig. 4c). In addition, lung metastasis was also found in BT20-LV-MFAP5 group in experiment 2 (Fig. 4d). The GFP mRNA expression of lung in BT20-LV-MFAP5 group was $36.9 \pm 6.78$ compared with $1.06 \pm 0.34$ of lung in BT20-LV-vehicle group (Fig. 4d). These results suggested that MFAP5 promoted the tumorigenesis and metastasis of BLBC in vivo.

\section{MFAP5 activated TGF- $\beta$ and Notch pathways}

The mRNA differentially expressed between BT20LV-vehicle and BT20-LV-MFAP5 cells were presented as $M$ (log ratio) and A (mean average) scales plots or volcano plots (Fig. 5a, b). The mRNA differentially expression levels $(\log 2 \mathrm{RPKM})$ in these two cells were shown in Heatmap (Fig. 5c). "There were 4138 significantly differentially expressed genes $(\mathrm{P}<0.05)$ between BT20-LV-vehicle and BT20-LV-MFAP5 cells." In addition, GO/KEGG pathway enrichment analysis on these genes identified 19 significant $(\mathrm{P}<0.05)$ pathways including TGF- $\beta$ and Notch pathways which were mediated in the activation of EMT (Fig. $5 \mathrm{~d}$, e). This result suggested that MFAP5 may play an important role in the activation of TGF- $\beta$ and Notch pathways. In order to prove this hypothesis, we examined the levels of Smad2/Smad3 (a vital signal in TGF- $\beta$ pathway) and two factors regulated by Notch pathway Hes1, Hes5 in BT20-LV-vehicle and BT20-LV-MFAP5 cells. Selected concentration of TGF- $\beta$ receptor inhibitor SB431542 $(10 \mu \mathrm{M})$ and Notch receptor inhibitor ly-411575 $(0.1 \mu \mathrm{M})$ were used for subsequent experiments (Additional file 3: Figure S2). As shown in Fig. 6a, Table 1, overexpression of MFAP5 promoted the phosphorylation of Smad2/Smad3, which was attenuated by TGF- $\beta$ or Notch inhibitor, and the degree of reduction by TGF- $\beta$ inhibitor group was more obvious than that in Notch inhibitor group. The qRT-PCR results showed that Hes1 and Hes5 were upregulated by overexpression of MFAP5 in the cells. Meanwhile, the levels of 

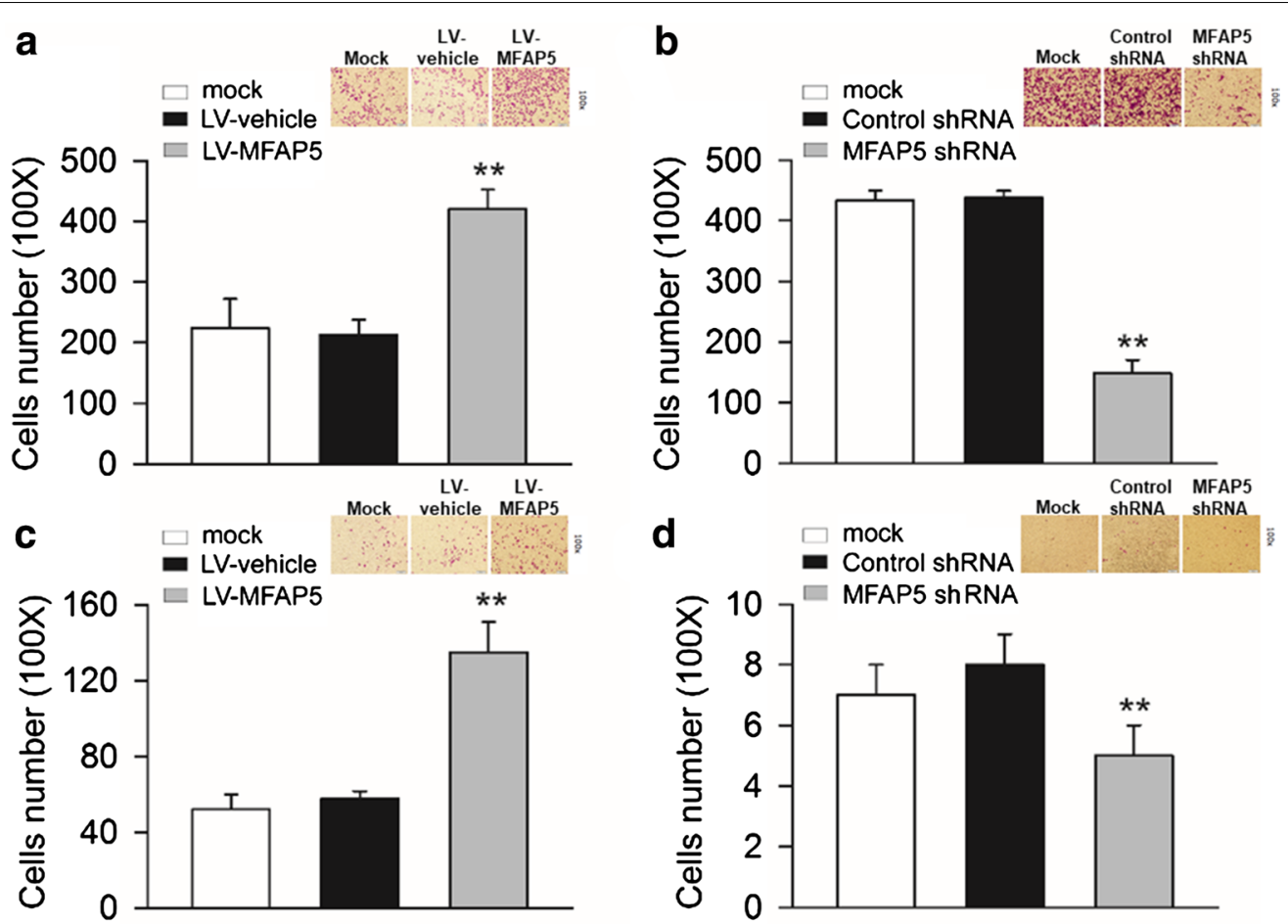

Fig. 2 MFAP5 regulates the invasion of BT20 and HS578T cells. Cell invasion was measured by transwell migration assay. a Compared to BT20-LV-vehicle cells, the invasion was increased of BT20-LV-MFAP5 cells. ${ }^{*} P<0.01$ vs LV-vehicle. b The invasion of HS578T cells in MFAP5 shRNA group was decreased compared with those in control shRNA group. ${ }^{*} P<0.01$ vs control shRNA. $\mathbf{c}$ The supernatant of BT20-LV-MFAP5 cells promoted the invasion of BT20 cells. ${ }^{*} P<0.01$ vs LV-vehicle. $\mathbf{d}$ HS578T cell invasion was inhibited by the supernatant of HS578T-MFAP5-shRNA cells. ${ }^{*} P<0.01$ vs control shRNA
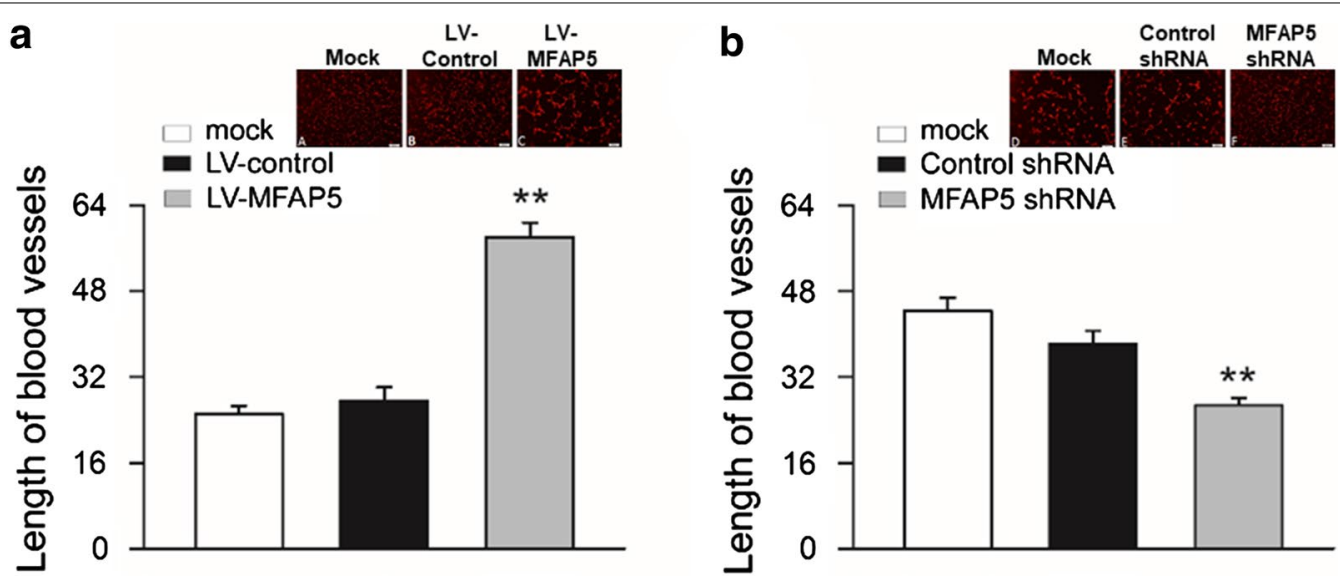

Fig. 3 MFAP5 regulated angiogenesis of HUVEC cells. a The length of blood vessels of HUVEC cells in the supernatant of BT20-LV-MFAP5 cells was increased compared with those in BT20-LV-vehicle cell supernatant. ${ }^{* *} P<0.01$ vs LV-vehicle. $\mathbf{b}$ Compared to HUVEC cells in the supernatant of HS578T-control-shRNA cells, length of blood vessels was decreased in the supernatant of HS578T-MFASP5-shRNA cells. ${ }^{*} P<0.01$ vs control shRNA

Hes 1 and Hes5 were down-regulated after treated with inhibitors, and Notch inhibitor exerted a better effect than TGF- $\beta$ inhibitor (Fig. $6 \mathrm{~b}$ ). These results suggested that MFAP 5 may promote the activation of both TGF- $\beta$ and Notch signaling pathways.
MPAP5 regulated epithelial-mesenchymal transition and motility of BLBC cells through TGF- $\beta$ and Notch pathways

EMT is a process that epithelial cells transform into mesenchymal cells by losing cellular morphology and 

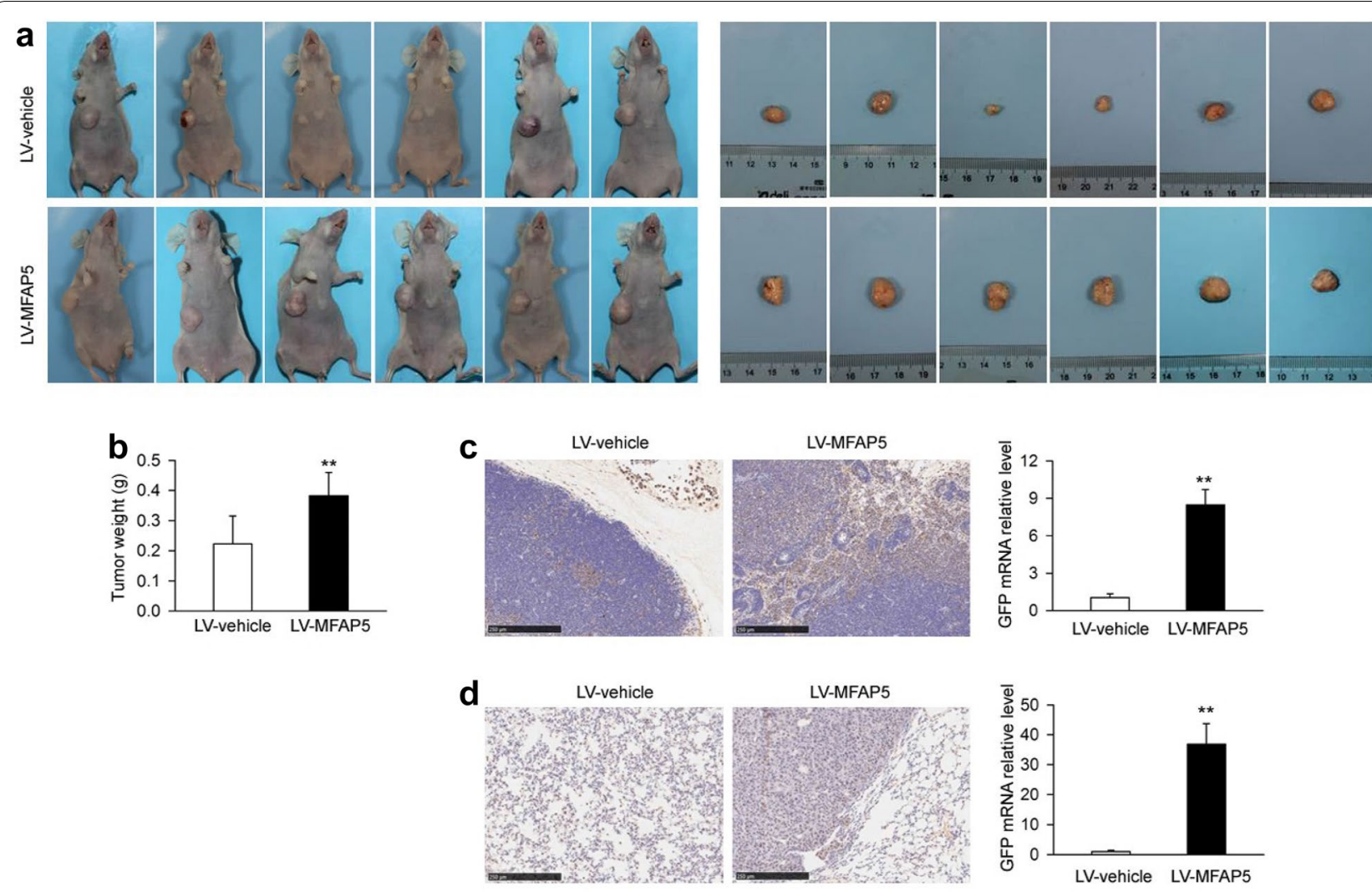

Fig. 4 MFAP5 regulated tumor proliferation and BT20 cell metastasis. a The volume of tumors in BT20-LV-MFAP5 nude mice was bigger than those in BT20-LV-vehicle group. b Compared with nude mice in BT20-LV-vehicle group, the weight of tumors in BT20-LV-MFAP5 group was significantly increased. ${ }^{* *} P<0.01$ vs LV-vehicle. $\mathbf{c} \| \mathrm{HC}$ and RT-PCR showed that the BT20 cells transferred to axillary lymph nodes in BT20-LV-MFAP5 nude mice were enhanced compared with these in BT20-LV-vehicle group. ${ }^{* *} P<0.01$ vs LV-vehicle. $\mathbf{d} I H C$ and RT-PCR demonstrated the lung metastasis of BT20 cells was increased in BT20-LV-MFAP5 nude mice. ${ }^{* *} P<0.01$ vs LV-vehicle

migratory capacity [28]. We then assessed the role of MFAP5 in EMT and examined whether the TGF- $\beta$ and Notch signaling pathways mediated MFAP5-induced EMT and metastasis. We tested the protein levels of the epithelial marker E-cadherin, $\mathrm{N}$-cadherin and the mesenchymal marker Type I Collagen of cells in BT20-LV-vehicle and BT20-LV-MFAP5 groups. The results indicated MFAP5 overexpression increased levels of N-cadherin, Type I collagen as well as decreased E-cadherin in the cells, which were dramatically revered by TGF- $\beta$ or Notch inhibitor (Fig. 7a). In EMT programming, pleiotropic EMT transcription factors form an interaction network and act in concert to regulate the EMT phenotype. MFAP5 markedly raised the mRNA levels of EMT transcription factors include Slug, Snail, Zeb1, Zeb2 and Twist which were largely decreased by SB431542 and ly-411575 (Fig. 7b). These results revealed that MFAP5 promoted EMT programming in BLBC cells and TGF- $\beta$ / Notch signaling pathways, at least in part.

Next, we examined whether TGF- $\beta$ and Notch signaling pathways were responsible for changes in cell motility regulated by MFAP5. We evaluated the influence of TGF- $\beta$ or Notch inhibitor on the biological behavior of cells by the CCK-8 and transwell assays. As illustrated in Fig. 8, the promotion effects of MFAP5 on BT20 cell proliferation and migration were partly abolished by TFG- $\beta$ or Notch inhibitor. These data suggested that MFAP5 might promote BLBC aggressive cellular traits via TGF- $\beta /$ Notch pathways.

\section{Discussion}

To date, the genetic profile and biologic basis of BLBC are poorly understood. Currently there is no targeted treatment measure for breast cancer. Therefore, more and more attention has been paid to the etiology, pathogenesis, especially invasion and metastasis of breast cancer. With the further research on the molecular mechanism of tumor cell growth, proliferation and apoptosis, it is an urgent task for breast cancer to find the biological marker of its targeted therapy. Activation of EMT is thought to initiate this early step in the metastatic cascade [29]. Notably, EMT has been demonstrated to be the most 


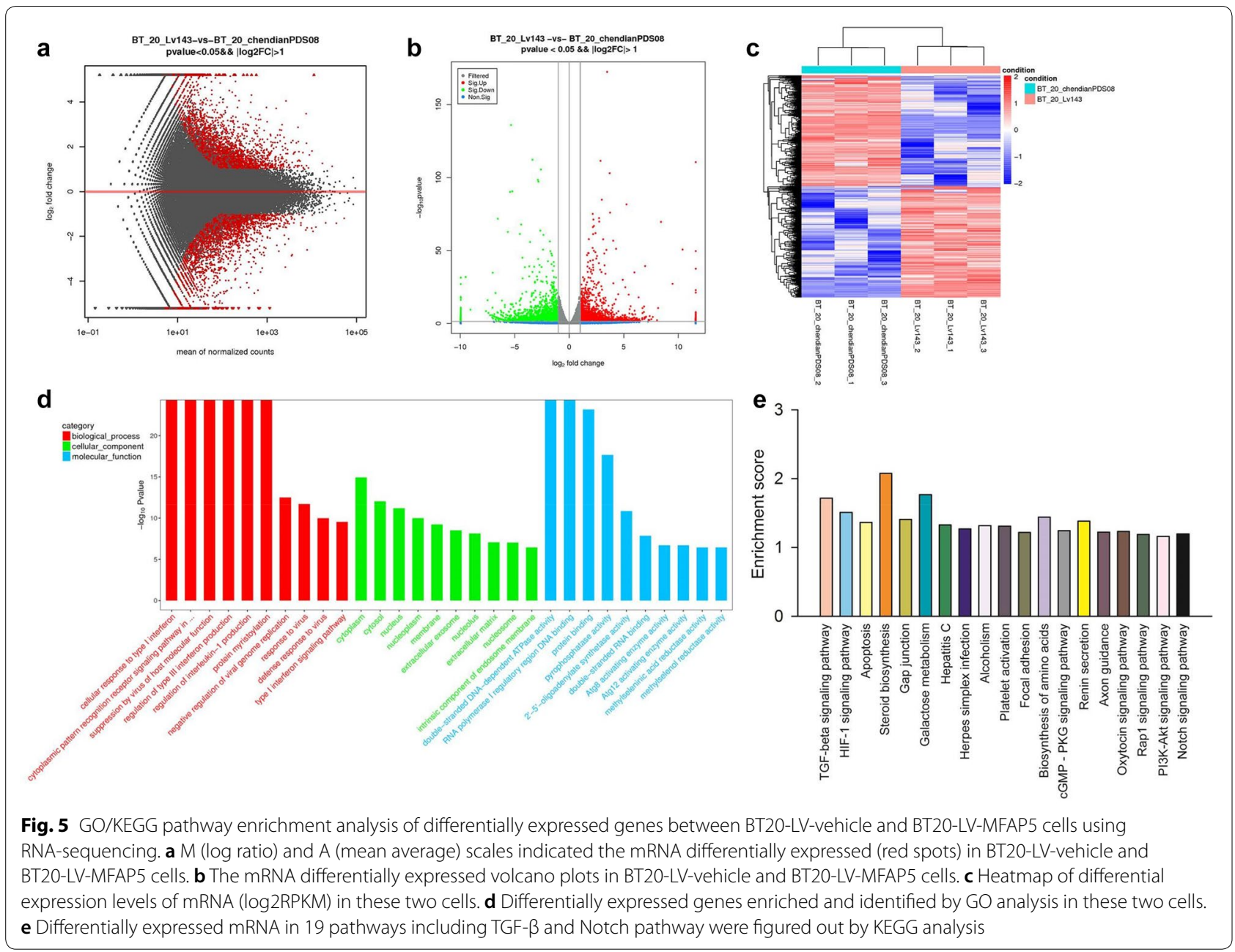

dominant pattern of intrinsic gene expression in BLBC [12]. Some studies have implicated that the development and progression of BLBC involves several signaling pathways such as TGF- $\beta$ [14], MEK/PI3K [23, 30], integrin [31], Notch pathways [32], and NF- $\mathrm{KB}$ [33]. It is reported that MFAP5 is associated with microfibrils and modulates endothelial cell behavior [18, 20]. MFAP5 also promotes angiogenesis and interacts with Notch1 by either activating or suppressing its activity, depending on the cell type involved [21,34]. In our previous study, we demonstrated that mRNA expression of MFAP5 was highly upregulated in BLBC [35]. In this study, we found that MFAP5 participated in carcinogenesis, development and progression of BLBC. The upregulation MFAP5 in BLBC was related to TNM staging and axillary lymph node metastasis. Up to date, no data show that expression of MFAP5 is associated with BLBC. This study contributes to the understanding of the molecular mechanism by which MFAP5 overexpression in BLBC promotes tumor progression. The results of this study suggest that MFAP5 may activate the TGF- $\beta$ and Notch signaling pathways to promote EMT, leading to an aggressive phenotype and tumor progression to metastasis.

Through the study of ovarian serous papillary adenocarcinoma, Mok et al. [22] showed that MFAP5 can be used as an independent predictor of poor prognosis in patients. It plays a very important role in the integration of elastic microfibrils and the regulation of endothelial cell behavior and cell survival. Previous studies have shown that MAGP2 (MFAF5) promotes tumor and endothelial cell survival and endothelial cell motility through $\alpha_{\mathrm{V}} \beta_{3}$ integrin-mediated signaling [20]. Results of this study revealed that MFAP5 over-expression accelerated the proliferative and metastatic properties of BLBC cells, and knockdown of MFAP5 had the opposite effect. Furthermore, we demonstrated that MFAP5 promoted the tumorigenesis and metastasis of BLBC in vivo by developing tumor xenograft and axillary lymph nodes, lung metastasis models. Specifically, qRT-PCR and Western blotting showed that MFAP5 
a

\section{p-Smad2/Smad3}

Actin

LV-vehicle +

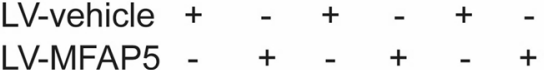
SB431542 - -++ly $-411575-\quad-\quad-\quad+\quad+$

b

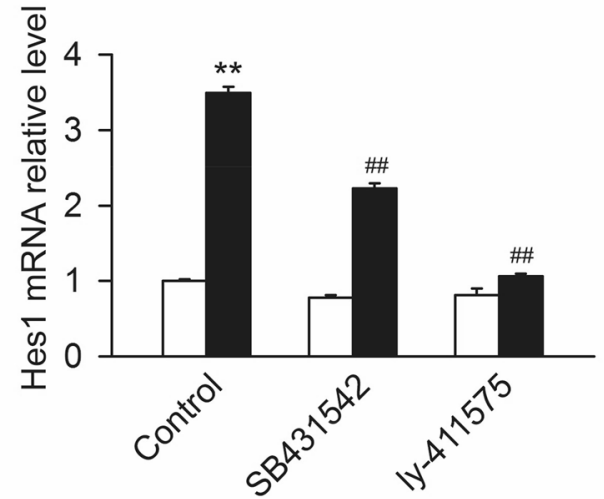

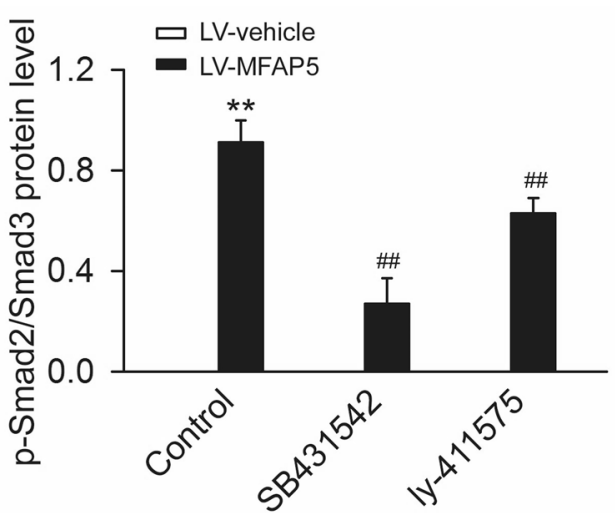

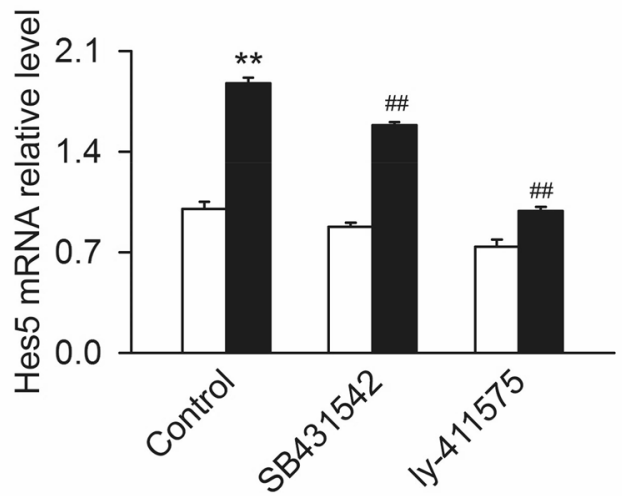

Fig. 6 MFAP5 regulated the activation of TGF- $\beta$ and Notch pathways in BT20 cells. BT20-LV-vehicle and BT20-LV-MFAP5 cells were treated with SB431542 or ly-411575 as indicated for $24 \mathrm{~h}$ and then collected to detect the protein level of $\mathrm{p}-\mathrm{Smad2} / \mathrm{Smad} 3$ by western blot and the mRNA levels of Hes 1 and Hes5 by RT-PCR. $\mathbf{a}, \mathbf{b}$ Compared with LV-vehicle group, overexpression of MFAP5 significantly improved the overexpression of p-Smad2/ Smad3 and the mRNA levels of Hes1, Hes5 which were strikingly attenuated by SB431542 and ly-411575. ${ }^{* *} P<0.01$ vs LV-vehicle control; ${ }^{\# \#} P<0.01$ vs LV-MFAP5 control

Table 1 Relative concentration of Smad2/3 expression in western blot test

\begin{tabular}{|c|c|c|c|c|c|c|c|}
\hline & Sample & NC & MEAP5 & $N C+S B 431542$ & MFAP5 + SB431542 & NC+ ly411575 & MFAP5 + ly411575 \\
\hline \multirow[t]{7}{*}{ p-Smad2/Smad3 } & \multirow[t]{3}{*}{ Gray value } & 0 & 302,830 & 0 & 126,610 & 0 & 206,209 \\
\hline & & 0 & 246,130 & 0 & 76,568 & 0 & 171,906 \\
\hline & & 0 & 292,443 & 0 & $79,480.3$ & 0 & 186,458 \\
\hline & Average & 0 & 280,468 & 0 & 94,219 & 0 & 188,191 \\
\hline & $\begin{array}{l}\text { Gray value of each molecule } \\
\text { relative to beta-actin (G1) }\end{array}$ & 0.00 & 0.91 & 0.00 & 0.28 & 0.00 & 0.63 \\
\hline & Compared with control group & 0.00 & 0.10 & 0.00 & 0.08 & 0.00 & 0.06 \\
\hline & $\begin{array}{l}\text { Compared with control group } \\
\text { (G1/NC) }\end{array}$ & 0.00 & 9.29 & 0.00 & 2.89 & 0.00 & 6.51 \\
\hline \multirow[t]{5}{*}{ Internal reference } & \multirow[t]{3}{*}{ Gray value } & 365,609 & 302,497 & 300,448 & 314,709 & 340,436 & 326,191 \\
\hline & & 303,144 & 316,665 & 357,508 & 336,392 & 292,601 & 284,270 \\
\hline & & 335,737 & 309,839 & 352,063 & 352,295 & 287,281 & 279,450 \\
\hline & Average & 334,830 & 309,667 & 336,673 & 334,465 & 306,773 & 296,637 \\
\hline & Compared with control group & 0.09 & 0.02 & 0.09 & 0.06 & 0.10 & 0.09 \\
\hline
\end{tabular}



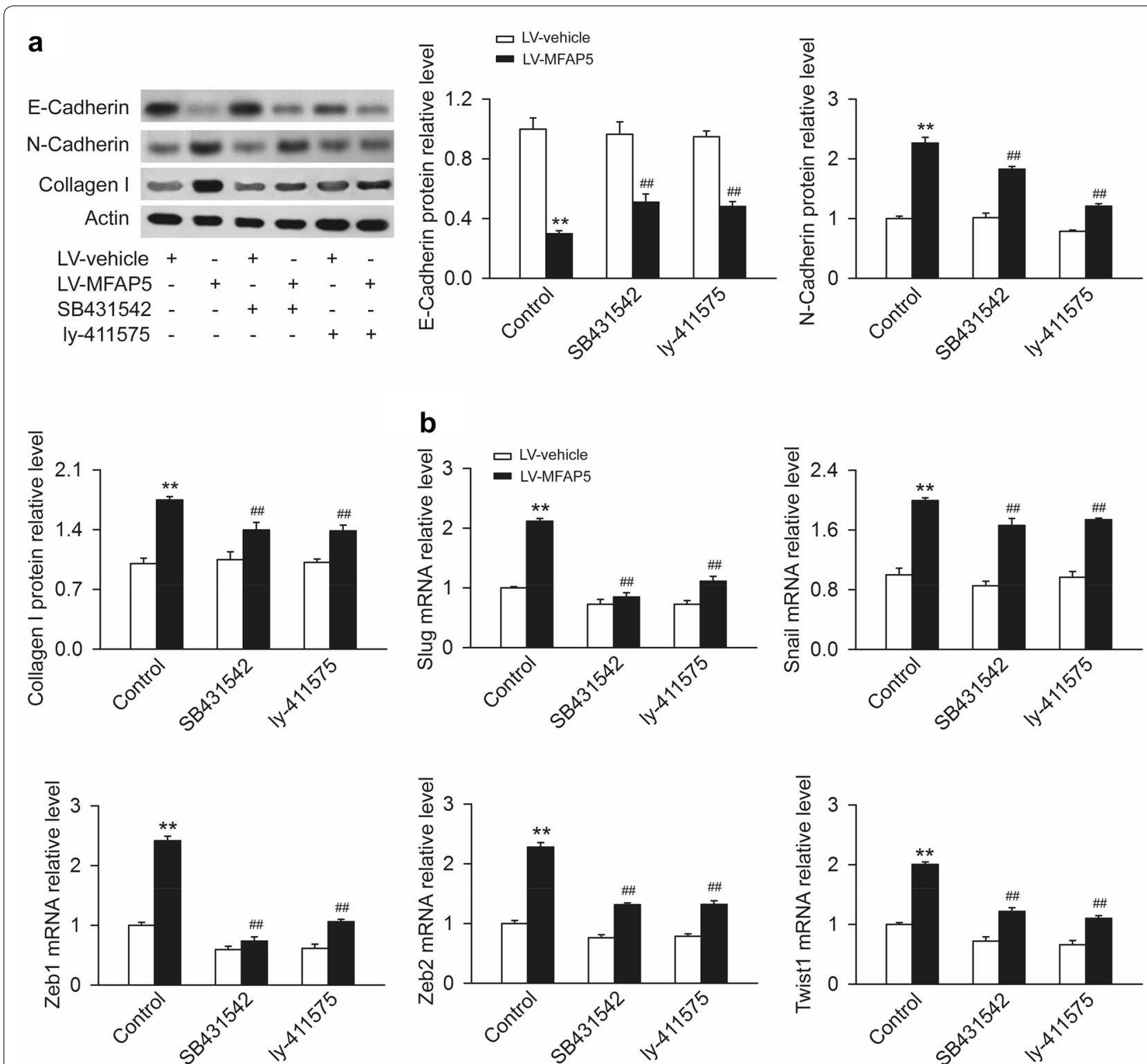

Fig. 7 MPAP5 regulated epithelial-mesenchymal transition of BLBC cells through TGF- $\beta$ and Notch pathways. BT20-LV-vehicle and BT20-LV-MFAP5 cells were treated with SB431542 or ly-411575 as indicated for $24 \mathrm{~h}$ and then collected to test the protein levels of E-cadherin, N-cadherin and Type I Collagen by Western blotting and the mRNA levels of Slug, Snail, Zeb1, Zeb2 and Twist by RT-PCR. a Overexpression of MFAP5 reduced the protein level of E-cadherin and increased N-cadherin and Collagen I expression in BT20 cells. SB431542 and ly-411575 partly abolished the inhibitory effect of MFAP5 on E-cadherin and the promoting role on N-cadherin and collagen I. ${ }^{* *} P<0.01$ vs LV-vehicle control; $\# P<0.01$ vs LV-MFAP5 control. b Compared with LV-vehicle group, the mRNA levels of Slug, Snail, Zeb1, Zeb2 and Twist were significantly increased in BT20 cells of LV-MFAP5 group which were decreased by SB431542 and ly-411575. ${ }^{* *} P<0.01$ vs LV-vehicle control; \#\# $P<0.01$ vs LV-MFAP5 control

upregulated the expression of N-cadherin and Type I Collagen and downregulated E-cadherin in BLBC cells. This provides evidence that MFAP5 promotes EMT in BLBC cells. Furthermore, similar results were found in xenograft mouse tumor sections, suggesting that MFAP5 promoted EMT in vivo.
EMT is a process that epithelial cells may transform into mesenchymal cells by losing cellular morphology and migratory capacity [36]. It plays an important role in the early stage of tumor metastasis and progression of cancer [37]. Identifying and understanding the signaling mechanisms that promote EMT may lead to novel therapeutic 

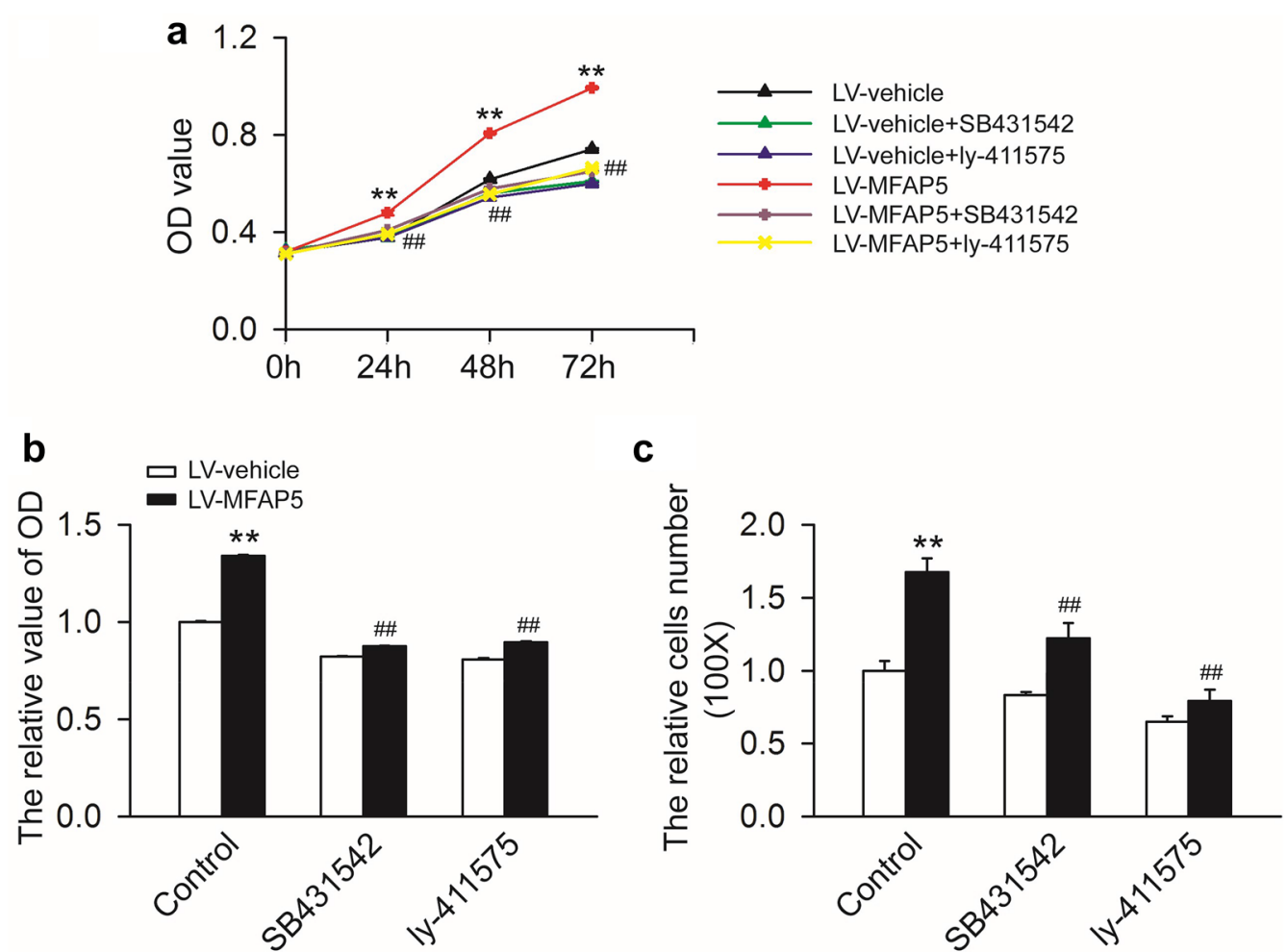

Fig. 8 TGF- $\beta$ and Notch pathways mediated the promoting effects of MPAP5 on BLBC cells motility. a BT20-LV-vehicle and BT20-LV-MFAP5 cells were treated with SB431542 or ly-411575 as indicated for 0, 24, 48 and $72 \mathrm{~h}$. Then the OD value of cells was measured. Overexpression of MFAP5 time dependently improved the OD value compared to LV-vehicle group. But OD value elevated by MFAP5 was strikingly weakened by SB431542 and ly-411575. ${ }^{* *} P<0.01$ vs LV-vehicle control; ${ }^{\#} P<0.01$ vs LV-MFAP5 control. b The OD value of cells at $72 \mathrm{~h}$ was presented. MFAP5 significantly increased cell OD value which was attenuated by SB431542 and ly-411575. ${ }^{* *} P<0.01$ vs LV-vehicle control; $\#$ P $<0.01$ vs LV-MFAP5 control. c BT20-LV-vehicle and BT20-LV-MFAP5 cells were treated with SB431542 or ly-411575 as indicated for $24 \mathrm{~h}$, and the invasion was measured by transwell migration assay. Compared with LV-vehicle group, the number of BT20 cell invasion was significantly increased in LV-MFAP5 group which were remarkably abolished by SB431542 and ly-411575. ${ }^{* *} P<0.01$ vs LV-vehicle control; ${ }^{\# \#} P<0.01$ vs LV-MFAP5 control

strategies to inhibit this cellular transformation in human cancer. There are several signal transduction pathways involved in the EMT process, such as transforming growth factor beta1 (TGF- $\beta$ ), NF- $\kappa B$, Wnt, and Notch $[38,39]$. It is reported that TGF- $\beta$ signaling pathway participates in many biological events and in the process of regulation of these cellular biology events, TGF- $\beta$ signal mainly interacts with other signaling pathways in order to obtain synergy or antagonism effect to exert its biological activities [40,41]. Smad is a group of intracellular proteins that are essential for the transmission of TGF- $\beta$ signals from the cell surface to the cell nucleus to promote the transcription of the target gene. A lot of evidences showed that TGF- $\beta$ can stimulate EMT in cancer cells and promote distant metastasis by depending or not depending on Smad2/3 signaling pathways [42]. Notch has been shown to be involved in a variety of cellular processes including cell division, cell fate specification, differentiation, apoptosis, migration, invasion, adhesion, epithelial cell polarity, stem cell maintenance, and angiogenesis [43]. Several lines of evidence support a role of Notch activation in BLBC tumors [44]. In our results, we explored the mechanism of MFAP5 biological function in EMT. We detected MFAP5 can promote the phosphorylation of $\mathrm{Smad} 2 / \mathrm{Smad} 3$. And the expression levels of Hes1 and Hes5, downstream effectors of Notch signaling pathway, were also increased. Inhibition of TGF- $\beta$ and Notch signaling pathways, the expression of $\mathrm{p}-\mathrm{Smad} 2 / \mathrm{p}-\mathrm{Smad} 3$, Hes1 and Hes5 were decreased. In addition, inhibition of the TGF- $\beta$ and Notch signaling can also block the expression of EMT transcription factors including Snail, Slug, Zeb1, Zeb2 and Twist, which could induce epithelial differentiation. At the same time, MFAP5-mediated migration, invasion and proliferation of BT20 cells were blocked by TGF- $\beta$ and Notch signaling pathways inhibitors. It implied that MFAP5 played an essential role in TGF- $\beta$ and Notch signaling in BLBC pathogenesis. However, the downstream mechanism underlying the links between MFAP5 and EMT program remains relatively unknown. 
Clearly, our study suggests that MFAP5 overexpression represents an oncogenic event that is responsible for the aggressive behaviors of BLBC cells. Thus, we assumed that MFAP5 might promote the procession of EMT by TGF- $\beta /$ Notch signaling pathway. However, further studies are still needed to elucidate novel mechanisms or cellular cues for MFAP5 eliciting TGF- $\beta /$ Notch signaling.

In summary, our findings reveal a novel gene MFAP5 involved in BLBC. It is a potential biomarker and a novel therapeutic target for BLBC patients at risk of metastasis. It plays an irreplaceable role in BLBC progression which may attribute to promoting EMT which enhances cell migration, invasion, and metastasis. Additional studies will be needed to elucidate the precise signaling pathway to provide important basis for using TGF- $\beta$ and Notch signaling pathways. These findings may prove to be clinically useful for developing a new therapeutic target for BLBC invasion and metastasis.

\section{Additional files}

Additional file 1: Table S1. The relative mRNA level of MFAP5 in BT20 and HS578T cells.

Additional file 2: Figure S1. The quantitative expression of MFAP5 mRNA in BT20 and HS578T cells after transfection. (A) BT20 cells transfected with MFAP5 lentivirus overexpressed MFAP5 compared to vehicle. ${ }^{* *} \mathrm{P}<0.01$ vs LV-vehicle. (B) Compared to control shRNA, HS578T cells transfected with MFAP5 shRNA expressed decreased mRNA level of MFAP5. ${ }^{* *} P<0.01$ vs control shRNA.

Additional file 3: Figure S2. The inhibitory effect ofSB431542 and ly-411575 on TGF- $\beta$ and Notch signaling pathways at different concentrations. BT20-LV-vehicle and BT20-LV-MFAP5 cells were treated with SB431542 or ly-411575 as indicated for 6 and $24 \mathrm{~h}$, then the cells were collected to detect the expression of p-Smad2/Smad3, Hes 1 and Hes5. (A) Immunofluorescence showed that SB431542 dose-dependently decreased the level of $\mathrm{p}-\mathrm{Smad} 2 / \mathrm{Smad} 3$ which was elevated by MFAP5. And at the concentration of $10 \mu \mathrm{M}, \mathrm{SB} 431542$ exhibited the largest inhibitory effect. (B) ly-411575 dose-dependently decreased the level of Hes1 and Hes5 induced by MFAP5 and the inhibitory effect was similar and more effective at 0.1 and $1 \mu \mathrm{M}$. ${ }^{*} P<0.01$ vs corresponding LV-vehicle; ${ }^{\# \#} P<0.01$ vs corresponding LV-MFAP5.

\section{Authors' contributions}

YW, XL and WZ conceived and designed experiments. YW and PW interpreted data. YW, PW, QZ and WC performed and experiments. YW and WZ wrote the manuscript. All authors read and approved the final manuscript.

\section{Author details}

1 Department of Breast Surgery, Changhai Hospital, Naval Medical University, 800 Xiangyin Road, Shanghai 200433, China. ${ }^{2}$ Department of Pathology, Maternal and Child Health Care Hospital, Huaian 223002, Jiangsu, China.

${ }^{3}$ Basic Medical College, Naval Medical University, Shanghai 200433, China.

${ }^{4}$ Department of Pathology, Changhai Hospital, Naval Medical University,

Shanghai 200433, China.

\section{Acknowledgements}

Dr. Yanmei Wu thanks all the members of this work for helpful discussion. We are grateful to the laboratory of the Department of Pathology for assistance with staining.

\section{Competing interests}

The authors declare that they have no competing interests.

\section{Availability of data and materials}

Please contact author for data requests.

\section{Consent for publication}

Not applicable.

Ethics approval and consent to participate

All animal protocols were approved by the Ethical Committee of Experimental Animals of Naval Medical University.

\section{Human and animal rights}

This article does not contain any studies with human participants performed by any of the authors.

\section{Funding}

This work was supported by National Natural Science Foundation of China (81272905).

\section{Publisher's Note}

Springer Nature remains neutral with regard to jurisdictional claims in published maps and institutional affiliations.

Received: 15 October 2018 Accepted: 15 February 2019

Published online: 07 March 2019

\section{References}

1. Rakha EA, Reis-Filho JS, Ellis IO. Basal-like breast cancer: a critical review. J Clin Oncol. 2008;26(15):2568.

2. Lehmann BD, Bauer JA, Chen X, Sanders ME, Chakravarthy AB, Shyr Y, Pietenpol JA. Identification of human triple-negative breast cancer subtypes and preclinical models for selection of targeted therapies. J Clin Invest. 2011;121(7):2750-67.

3. Bianchini G, Balko J, Mayer I, Sanders ME, Gianni L. Triple-negative breast cancer: challenges and opportunities of a heterogeneous disease. Nat Rev Clin Oncol. 2016;13(11):674

4. Dent R, Trudeau M, Pritchard KI, Hanna WM, Kahn HK, Sawka CA, Lickley LA, Rawlinson E, Sun P, Narod SA. Triple-negative breast cancer: clinical features and patterns of recurrence. Clin Cancer Res. 2007;13(15):4429-34.

5. Chung S, Jin Y, Han B, Qu Y, Gao B, Giuliano AE, Cui X. Identification of EGF-NF-KB-FOXC1 signaling axis in basal-like breast cancer. Cell Commun Signal. 2017;15(1):22.

6. Jensen TW, Ray T, Wang J, Li X, Naritoku WY, Han B, Bellafiore F, Bagaria SP, Qu A, Cui X, et al. Diagnosis of basal-like breast cancer using a FOXC1based assay. JNCI. 2015;107(8):148.

7. Bidard FC, Conforti R, Boulet T, Michiels S, Delaloge S, André F. Does triplenegative phenotype accurately identify basal-like tumour? An immunohistochemical analysis based on 143 'triple-negative' breast cancers. Ann Oncol. 2007;18(7):1285-6.

8. Rakha E, Ellis I, Reis-Filho J. Are triple-negative and basal-like breast cancer synonymous? Clin Cancer Res. 2008;14(2):618.

9. Ray PS, Wang J, Qu Y, Sim M-S, Shamonki J, Bagaria SP, Ye X, Liu B, Elashoff D, Hoon DS, et al. FOXC1 is a potential prognostic biomarker with functional significance in basal-like breast cancer. Can Res. 2010;70(10):3870-6.

10. Sørlie T, Perou CM, Tibshirani R, Aas T, Geisler S, Johnsen H, Hastie T, Eisen $M B$, van de Rijn M, Jeffrey SS, et al. Gene expression patterns of breast carcinomas distinguish tumor subclasses with clinical implications. Proc Natl Acad Sci USA. 2001;98(19):10869-74.

11. Gazinska P, Grigoriadis A, Brown JP, Millis RR, Mera A, Gillett CE, Holmberg LH, Tutt AN, Pinder SE. Comparison of basal-like triple-negative breast cancer defined by morphology, immunohistochemistry and transcriptional profiles. Mod Pathol. 2013;26:955.

12. Matysiak M, Kapka-Skrzypczak L, Jodlowska-Jedrych B, Kruszewski M. EMT promoting transcription factors as prognostic markers in human breast cancer. Arch Gynecol Obstet. 2017;295(4):817-25. 
13. Lamouille S, Xu J, Derynck R. Molecular mechanisms of epithelial-mesenchymal transition. Nat Rev Mol Cell Biol. 2014;15(3):178-96.

14. Li NS, Zou JR, Lin H, Ke R, He XL, Xiao L, Huang D, Luo L, Lv N, Luo Z. LKB1/ AMPK inhibits TGF-beta1 production and the TGF-beta signaling pathway in breast cancer cells. Tumour Biol. 2016;37(6):8249-58.

15. Cheng H, Wang S, Feng R. STIM1 plays an important role in TGF-betainduced suppression of breast cancer cell proliferation. Oncotarget. 2016;7(13):16866-78.

16. Peng GL, Tian Y, Lu C, Guo H, Zhao XW, Guo YW, Wang LQ, Du QL, Liu CP. Effects of Notch-1 down-regulation on malignant behaviors of breast cancer stem cells. J Huazhong Univ Sci Technolog Med Sci. 2014;34(2):195-200

17. Zhao L, Zhang QY, Luan X, Huang X, Zhao S, Zhao H. Relationship between the expression of Notch1 and EZH2 and the prognosis of breast invasive ductal carcinoma. Genet Mol Res. 2016;15:1. https://doi. org/10.4238/gmr.15017464.

18. Lemaire R, Bayle J, Mecham RP, Lafyatis R. Microfibril-associated MAGP-2 stimulates elastic fiber assembly. J Biol Chem. 2007;282(1):800-8.

19. Kielty CM, Sherratt MJ, Shuttleworth CA. Elastic fibres. J Cell Sci. 2002:115(14):2817-28.

20. Spivey KA, Banyard J. A prognostic gene signature in advanced ovarian cancer reveals a microfibril-associated protein (MAGP2) as a promoter of tumor cell survival and angiogenesis. Cell Adhes Migr. 2010;4(2):169-71.

21. Albig AR, Becenti DJ, Roy TG, Schiemann WP. Microfibril-associate glycoprotein-2 (MAGP-2) promotes angiogenic cell sprouting by blocking notch signaling in endothelial cells. Microvasc Res. 2008;76(1):7-14.

22. Mok SC, Bonome T, Vathipadiekal V, Bell A, Johnson ME, Wong K-K, Park D-C, Hao K, Yip DKP, Donninger $\mathrm{H}$, et al. A gene signature predictive for outcome in advanced ovarian cancer identifies a survival factor: microfibril-associated glycoprotein 2. Cancer Cell. 2009;16(6):521-32.

23. Leung CS, Yeung TL, Yip KP, Pradeep S, Balasubramanian L, Liu J, Wong KK, Mangala LS, Armaiz-Pena GN, Lopez-Berestein G, et al. Calcium-dependent FAK/CREB/TNNC1 signalling mediates the effect of stromal MFAP5 on ovarian cancer metastatic potential. Nat Commun. 2014;5:5092.

24. Yang X, Wu K, Li S, Hu L, Han J, Zhu D, Tian X, Liu W, Tian Z, Zhong L, et al. MFAP5 and TNNC1: potential markers for predicting occult cervical lymphatic metastasis and prognosis in early stage tongue cancer. Oncotarget. 2017;8(2):2525-35.

25. Wu YM, Hu W, Wang Y, Wang N, Gao L, Chen ZZ, Zheng WQ. Exploring novel targets of basal-like breast carcinoma by comparative gene profiling and mechanism analysis. Breast Cancer Res Treat. 2013;141:23-32.

26. Anders S, Huber W. Differential expression of RNA-Seq data at the gene level—the DESeq package. Heidelberg: European Molecular Biology Laboratory (EMBL); 2012.

27. Fu C, Luo J, Ye S, Yuan Z, Li S. Integrated lung and tracheal mRNA-Seq and miRNA-Seq analysis of dogs with an avian-like H5N1 canine influenza virus infection. Front Microbiol. 2018:9:303.

28. Thiery JP, Sleeman JP. Complex networks orchestrate epithelial-mesenchymal transitions. Nat Rev Mol Cell Biol. 2006;7(2):131-42.
29. Puisieux A, Brabletz T, Caramel J. Oncogenic roles of EMT-inducing transcription factors. Nat Cell Biol. 2014;16(6):488-94.

30. Rexer BN, Ghosh R, Arteaga CL. Inhibition of PI3K and MEK: it is all about combinations and biomarkers. Clin Cancer Res. 2009;15(14):4518-20.

31. Lu S, Simin K, Khan A, Mercurio AM. Analysis of integrin beta4 expression in human breast cancer: association with basal-like tumors and prognostic significance. Clin Cancer Res. 2008;14(4):1050-8.

32. Lee CW, Simin K, Liu Q, Plescia J, Guha M, Khan A, Hsieh C-C, Altieri DC. A functional Notch-survivin gene signature in basal breast cancer. Breast Cancer Res. 2008;10(6):R97.

33. Wang J, Ray PS, Sim MS, Zhou XZ, Lu KP, Lee AV, Lin X, Bagaria SP, Giuliano $A E$, Cui X. FOXC1 regulates the functions of human basal-like breast cancer cells by activating NF-kB signaling. Oncogene. 2012;31(45):4798-802.

34. Miyamoto A, Lau R, Hein PW, Shipley JM, Weinmaster G. Microfibrillar proteins MAGP-1 and MAGP-2 induce Notch1 extracellular domain dissociation and receptor activation. J Biol Chem. 2006;281(15):10089-97.

35. Wu Y, Li X, Hu W, Wang N, Gao L, Chen Z, Zheng W. Microfibril-associated protein 5 (MFAP5): a potential novel marker in the extracellular matrix distinguishing basal-like breast carcinoma from breast cancer. Anal Quant Cytopathol. 2016:28(3):175-82.

36. Li J, Zhou BP. Activation of $\beta$-catenin and Akt pathways by Twist are critical for the maintenance of EMT associated cancer stem cell-like characters. BMC Cancer. 2011;11:49.

37. Tiwari N, Gheldof A, Tatari M, Christofori G. EMT as the ultimate survival mechanism of cancer cells. Semin Cancer Biol. 2012;22(3):194-207.

38. Jing Y, Han Z, Zhang S, Liu Y, Wei L. Epithelial-mesenchymal transition in tumor microenvironment. Cell Biosci. 2011:1:29.

39. Liu CC, Cai DL, Sun F, Wu ZH, Yue B, Zhao SL, Wu XS, Zhang M, Zhu XW, Peng ZH, et al. FERMT1 mediates epithelial-mesenchymal transition to promote colon cancer metastasis via modulation of $\beta$-catenin transcriptional activity. Oncogene. 2017:36(13):1779-92.

40. Janda E, Lehmann K, Killisch I, Jechlinger M, Herzig M, Downward J, Beug H, Grünert S. Ras and TGF[beta] cooperatively regulate epithelial cell plasticity and metastasis: dissection of Ras signaling pathways. J Cell Biol. 2002;156(2):299-313.

41. Zavadil J, Cermak L, Soto-Nieves N, Böttinger EP. Integration of TGF-beta/ Smad and Jagged 1 /Notch signalling in epithelial-to-mesenchymal transition. EMBO J. 2004:23(5):1155-65.

42. Padua D, Zhang XHF, Wang Q, Nadal C, Gerald WL, Gomis RR, Massagué J. TGFbeta primes breast tumors for lung metastasis seeding through angiopoietin-like 4. Cell. 2008;133(1):66-77.

43. Bolós V, Grego-Bessa J, de la Pompa JL. Notch signaling in development and cancer. Endocr Rev. 2007;28(3):339-63.

44. Dontu G, Jackson KW, McNicholas E, Kawamura MJ, Abdallah WM, Wicha MS. Role of Notch signaling in cell-fate determination of human mammary stem/progenitor cells. Breast Cancer Res. 2004;6(6):R605.

Ready to submit your research? Choose BMC and benefit from

- fast, convenient online submission

- thorough peer review by experienced researchers in your field

- rapid publication on acceptance

- support for research data, including large and complex data types

- gold Open Access which fosters wider collaboration and increased citations

- maximum visibility for your research: over $100 \mathrm{M}$ website views per year

At BMC, research is always in progress.

Learn more biomedcentral.com/submissions 